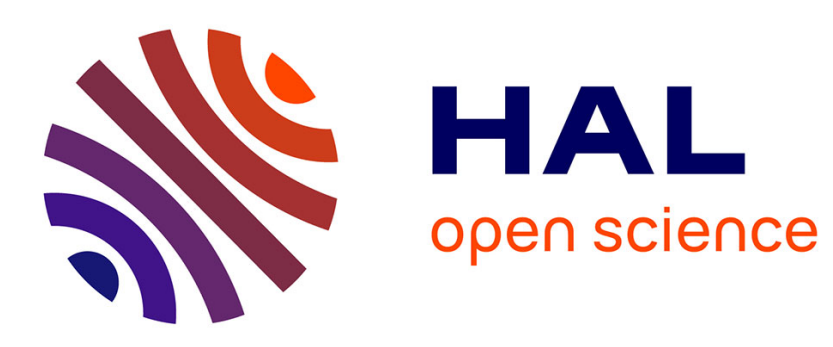

\title{
Accurate index profile measurements for fiber bragg gratings and sensor application
}

Xavier Chapeleau, Dominique Leduc, Pascal Casari, Yves Quinquempois, Josselin Lebon, Francisco Lopez, Cyril Lupi, Christian Boisrobert

\section{- To cite this version:}

Xavier Chapeleau, Dominique Leduc, Pascal Casari, Yves Quinquempois, Josselin Lebon, et al.. Accurate index profile measurements for fiber bragg gratings and sensor application. Symposium on Optical Fiber Measurements, 2004, Boulder, United States. 10.1109/SOFM.2004.183503 . hal-01007832

\section{HAL Id: hal-01007832 \\ https://hal.science/hal-01007832}

Submitted on 28 Apr 2018

HAL is a multi-disciplinary open access archive for the deposit and dissemination of scientific research documents, whether they are published or not. The documents may come from teaching and research institutions in France or abroad, or from public or private research centers.
L'archive ouverte pluridisciplinaire HAL, est destinée au dépôt et à la diffusion de documents scientifiques de niveau recherche, publiés ou non, émanant des établissements d'enseignement et de recherche français ou étrangers, des laboratoires publics ou privés. 


\title{
Accurate index profile measurements for fiber Bragg gratings and sensor application
}

\author{
Xavier Chapeleau ${ }^{1}$, Dominique Leduc ${ }^{1}$, Pascal Casari ${ }^{2}$, Yves Quiquempois ${ }^{3}$, \\ Josselin Lebon $^{2}$, Francisco Lopez ${ }^{3}$, Cyril Lupi ${ }^{1}$ and Christian Boisrobert ${ }^{1}$ \\ ${ }^{1}$ Institut de Recherche en Electrotechnique et Electronique de Nantes-Atlantique (IREENA), \\ Université de Nantes, 2 rue de la Houssinière, 44300 Nantes, France \\ ${ }^{2}$ Institut de Recherche en Génie Civil et Mécanique (GéM), \\ Université de Nantes, 2 rue de la Houssinière, 44300 Nantes, France \\ ${ }^{3}$ Laboratoire de Physique des Lasers, Atomes et Molécules (PhLAM), UMR CNRS 8523, \\ Université des Sciences et Technologies de Lille, 59655 Villeneuve d Ascq, France \\ xavier.chapeleau@univ-nantes.fr
}

\begin{abstract}
This paper demonstrates that the combination of the optical low-coherence reflectometry and the layer-peeling algorithm is a suitable method to measure the index profile of fiber Bragg gratings. The high sensitivity of this technique permits to detect index modulation amplitude as small as $110^{-5}$. The phase of the grating can also be determined accurately and we demonstrate that this measurement permits to retrieve the axial strain distribution for gratings subjected to strain gradient.
\end{abstract}

\section{Introduction}

The determination of the index profiles of Fiber Bragg Gratings (FBGs) is more and more desired in order to improve their spectral and temporal performances in particular for high bite rate transmission systems. Some methods as tranverse diffraction technique, local heating technique or Optical Space Domain Reflectometry (OSDR) can be used but they are more suitable for highly reflective gratings. In general, their sensitivity is not sufficient to dectect index modulation amplitude below $110^{-4}$. An alternative method is based on the association of the Optical Low-Coherence Reflectometry (OLCR) and an inverse scattering algorithm called layer-peeling [1]. The OLCR measures the complex reflection coefficient which is necessary for the layer-peeling to retrieve the index profile of FBGs. The aim of this paper is to demonstrate the efficiency of this method. The sensitivity of the index modulation amplitude and phase measurements are studied. An application of our method to the determination of axial strain distribution is also presented.

\section{OLCR and layer-peeling}

FBGs are a periodic refractive index modulation in the core of optical fibers, induced by UV exposure. This index perturbation $\Delta \mathrm{n}(z)$ is generally written as the following form :

$$
\Delta \mathrm{n}(z)=\Delta \mathrm{n}_{\mathrm{DC}}(z)+\Delta \mathrm{n}_{\mathrm{AC}}(z) \cos \left[\frac{2 \pi}{\Lambda_{0}} z+\frac{2 \pi}{\Lambda_{0}^{2}} \int_{0}^{z}\left(\Lambda(z \prime)-\Lambda_{0}\right) d z \prime\right]
$$

where $\Delta \mathrm{n}_{\mathrm{AC}}$ is the index modulation amplitude and $\Delta \mathrm{n}_{\mathrm{DC}}$ is the mean index variation. $\Lambda(z)$ is the period of the grating. For uniform gratings $\Lambda(z)=\Lambda_{0}$ and for gratings with linear chirp $\Lambda(z)$ is expressed as $\Lambda(z)=\alpha z+\Lambda_{0}$.

The layer-peeling algorithm is based on the coupled mode theory. By knowning the complex reflexion coefficient, this algorithm gives the coupling coefficient $\Omega(z)$ which is expressed by the following relation :

$$
\Omega(z)=\frac{\eta \pi}{2 \mathrm{n}_{\mathrm{co}} \Lambda_{0}} \Delta \mathrm{n}_{\mathrm{AC}}(z) e^{-i \Psi(z)} \quad \text { with } \quad \Psi(z)=\frac{2 \pi \eta}{\mathrm{n}_{\mathrm{co}} \Lambda_{0}} \int_{0}^{z} \Delta \mathrm{n}_{\mathrm{DC}}(z \prime) d z \prime+\frac{2 \pi}{\Lambda_{0}^{2}} \int_{0}^{z}\left(\Lambda(z \prime)-\Lambda_{0}\right) d z \prime
$$

where $\mathrm{n}_{\mathrm{co}}$ is the unperturbed effective index of the fiber and $\eta$ the fraction of the modal power contained in the fiber core. $\Psi(z)$ corresponds to the phase of the grating. The equation 2 shows that the index modulation amplitude and the phase of the grating can easily be determined. However, the layer-peeling algorithm can only be used if the complex reflexion coefficient of FBGs is measured accurately. The OLCR is admitted as a suitable method to do it. Severals papers [2, 3, 4] have demonstrated its efficiency. A description of our experimental set-up and the first results we obtained can be found in [5]. 


\section{Performance of the OLCR technique}

As all inverse scattering algorithms, the layer-peeling is hindered due to the presence of noise in the complex reflexion coefficient measurements, especially for high reflexion coefficient. So, it can't determine correctly the index profile of FBGs having reflexion coefficient upper than $90 \%$. It's the highest limit we obtained so that the index profiles determined by the layer-peeling and the transverse diffraction technique (Krugg method [6]) are in good agreement. The figure 1 shows the index modulation amplitudes obtained by both methods for a uniform FBG whose reflexion coefficient is equal to $90 \%$. We can notice that the index profiles exhibit some ripples. They are not an artefact of the layer-peeling algorithm since they appear also for the transverse diffraction measurement. They are due to internal reflexion in the phase mask. To evaluate the repetability of ten successives measurements, the maximum relative difference has been calculated. In the figure 1, we can see that these differences remain lower than $3 \%$, which demonstrates the high repetability of our measurements.

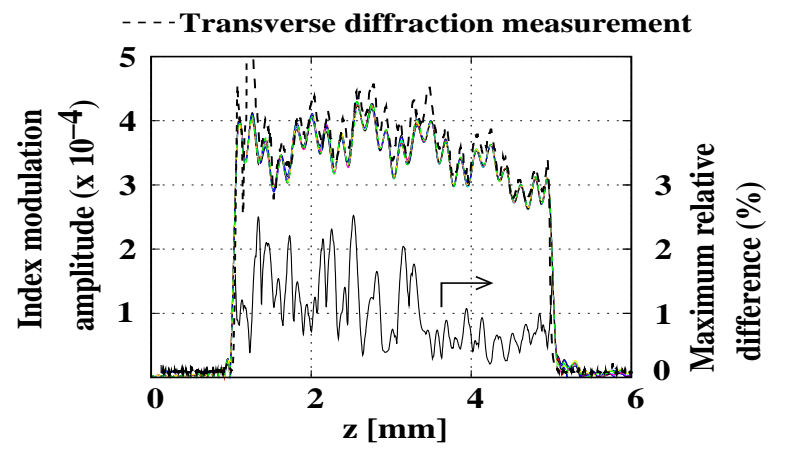

Figure 1: Index modulation amplitude. $\mathrm{R}=90 \%$ (10 measurements)

It's clear that the layer-peeling algorithm is most suitable for weak gratings. However, if the coupling strength becomes too small, the noise can hinder the index profile reconstruction. To illustrate this fact, the figure 2 shows the index profile of a grating whose reflexion coefficient is equal to only $1 \%$. In this case, the index modulation amplitude doesn't exceed $2.510^{-5}$ and we can see that the maximum relative difference is a little higher than in the previous case. Nevertheless, it remains lower than $4 \%$. It's important to emphasize that the index profile presented in this figure can't be detected by the diffration technique. This proves the high sensitivity of our method.

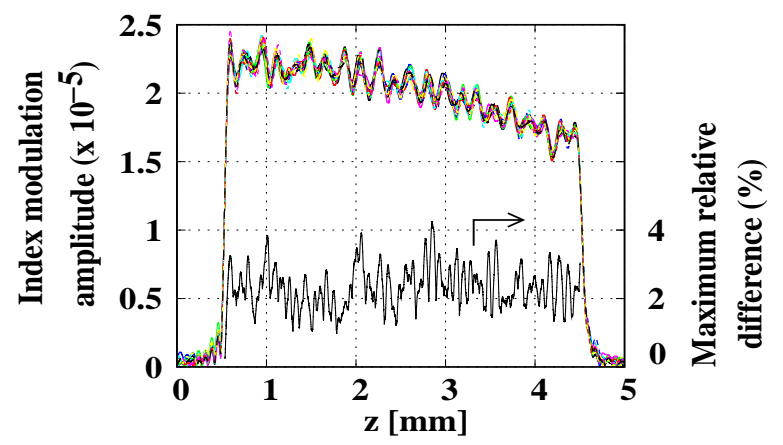

Figure 2: Index modulation amplitude. $\mathrm{R}=1 \%$ (10 measurements)

To show more precisely the sensitivity, the index profile of a particular grating has been measured. Seven uniform, $500 \mu \mathrm{m}$ long, gratings were written successively and the index modulation amplitude was divided approximately by two from one grating to the next. The measured index profile reveals well this step structure (cf. figure 3). The first step has a high index modulation amplitude close to $110^{-3}$. The last step is very small since the index modulation amplitude is below $210^{-5}$. This results demonstrate that the association of the layerpeeling and OLCR techniques is perfectly suitable for the measurement of index profile whose amplitude is as small as $110^{-5}$. 


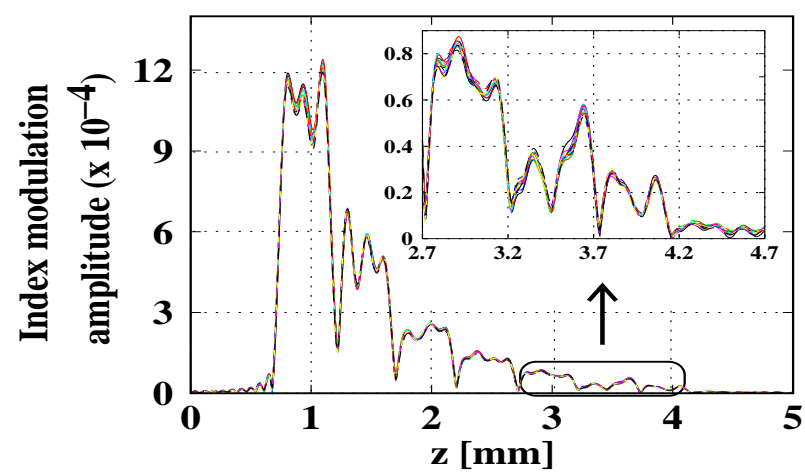

Figure 3: Index modulation amplitude (10 measurements).

\section{Phase grating measurement}

An other advantage of our technique is that the phase of the grating can be measured. For example, a $\pi$ phaseshift grating has been studied. Theoretically, if we assume that the mean index $\Delta \mathrm{n}_{\mathrm{DC}}(z)$ is constant along the grating, the phase grating can be modeled by :

$$
\left\{\begin{array}{lll}
\Psi(z)=\frac{2 \pi \eta}{\mathrm{n}_{\mathrm{co}} \Lambda_{0}} \Delta \mathrm{n}_{\mathrm{DC}} z & \text { if } & 0<z<z_{0} \\
\Psi(z)=\frac{2 \pi \eta}{\mathrm{n}_{\mathrm{co}} \Lambda_{0}} \Delta \mathrm{n}_{\mathrm{DC}} z+\pi & \text { if } & z_{0}<z<\mathrm{L}
\end{array}\right.
$$

where $z_{0}$ is the position of the phase-shift in the grating.

The figure 4 shows the phase we obtained for this grating. This phase is linear with $z$ and in the middle of the grating, we can see the phase-shift which expands over $50 \mu \mathrm{m}$. Sometimes, it can be less long, this depends on the fabrication process. The figure in insert shows that the amplitude of the phase-shift is close to $\pi$ as expected. Thus, this result demonstrates the efficiency of our method to measure the phase grating.

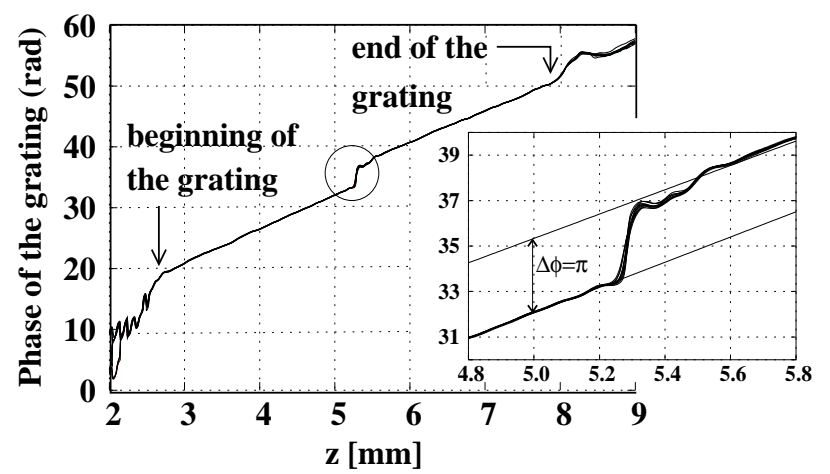

Figure 4: Phase of the $\pi$ phase-shift grating (10 measurements).

\section{Axial strain distribution measurement}

When FBGs are subjected to an axial force, both the grating period and the refractive index are modified. Indeed, the refractive index is changed due to the photoelastic effect :

$$
\Delta \mathrm{n}_{\mathrm{DC}}=-\frac{\mathrm{n}_{\mathrm{co}}^{3}}{2}\left[\mathrm{P}_{12}-\nu\left(\mathrm{P}_{11}+\mathrm{P}_{12}\right)\right] \epsilon(\mathrm{z})
$$

where ${ }_{11}, \mathrm{P}_{12}$ are the strain-optic coefficients and $\nu$ the Poisson's ratio of the FBG. The grating period variation is related to the strain by the following relation :

$$
\frac{\Delta \Lambda(z)}{\Lambda_{0}}=\epsilon(z)
$$


Taking into account these two effects, the phase of the grating modified by an axial strain becomes :

$$
\Psi(z)=\frac{2 \pi}{\Lambda_{0}}\left\{1-\frac{\eta \mathrm{n}_{\mathrm{co}}^{2}}{2}\left[P_{12}-\nu\left(P_{11}+P_{12}\right)\right]\right\} \int_{0}^{z} \epsilon(z \prime) d z \prime
$$

So, the axial strain can be obtained simply by differentiating the phase. In order to test this method, an uniform FBG, $4 \mathrm{~mm}$ long, has been embedded in a parallelepipedal sample of epoxy resin in which two holes have been drilled symmetrically beside the sensor (figure 5). This scheme permits to obtain a non-uniform strain along the grating.

Figure 6(a) shows the strains obtained from different tensile loads. Without applied force, the strain curve is a straight line despite some small ripples. For a force equal to $1200 \mathrm{~N}$, the curve appears rounded as shows it the figure 6(b). This indicates that the strain is not uniform along the grating. The dissymetry of the measurement is only due to the fact that the two holes are not perfectly centered to the middle of the FBG.

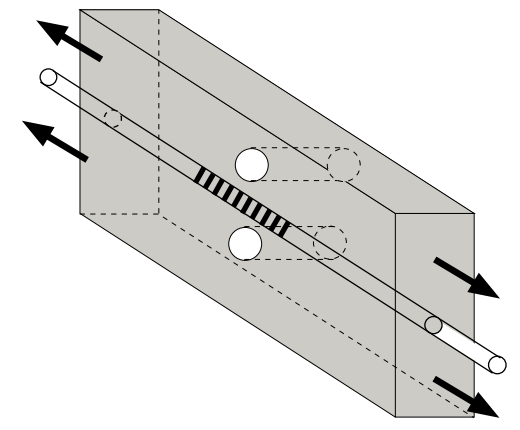

Figure 5: Sketch of the embedded FBG

A finite element model (FEM) has been used in order to predict the strain evolution along the grating. The figure 6(b) shows that the strain obtained by FEM follows exactly the same evolution as the ones measured with the FBG sensor. The excellent agreement between the two results demontrates the validity of our method for non uniform axial strain measurements.

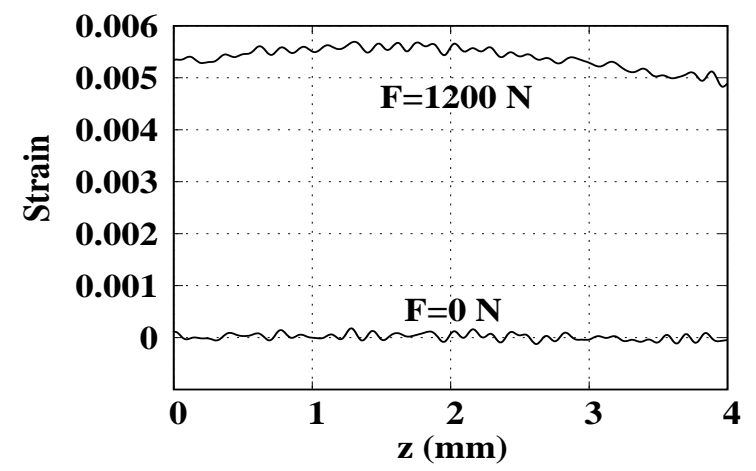

(a) Strain along the grating with and without applied traction force

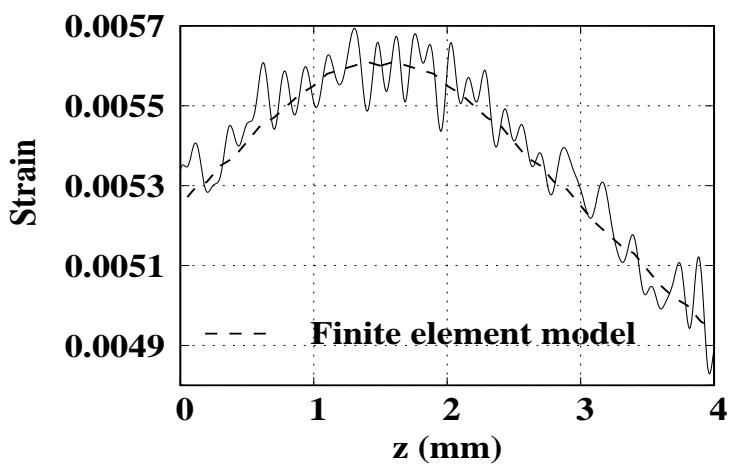

(b) Comparison between strain measured and calculated by FEM

Figure 6: Strain distribution measurement.

\section{Conclusion}

The association of OLCR and layer-peeling is an efficient method for the index profile of FBGs characterization. Thanks to its high sensitivity, index modulation amplitude variations as small as $110^{-5}$ can be detected. Moreover, this method gives the phase of the grating, which permits to localize phase-shift or to measure the mean index variation in the case of uniform gratings. Such phase grating measurements can also be used in sensor applications. Indeed, we demonstrated that non-uniform axial strain distribution can be measured.

\section{References}

1. J. Skaar, L. Wang et T. Erdogan,"On the Synthesis of Fiber Bragg Gratings by Layer Peeling", IEEE J. Quantum Electron., 37(2), 165-173 (2001).

2. D. Leduc, X. Chapeleau, C. Lupi, R. Le Ny et C. Boisrobert, "Accurate low-coherence interferometric relative group delay and refectance measurements; characterization of a free space optics multiplexeur/demultiplexeur", Journal of Optics A : Pure and Applied Optics, 2, 51-55, (2003).

3. S. Dyer and K. Rochford,"Low-coherence interferometric measurements of the dispersion of multiple fi ber Bragg gatings", IEEE Photonics Technology Letters,13(3), 230-232, (2001).

4. P. Giaccari, H.G. Limberger et R. Salathé, "Local coupling-coeffi cient characterization in fi ber Bragg gratings", Opt. Lett. , 28(8), 598-600 (2003).

5. X. Chapeleau, D. Leduc, C. Lupi, R. Le Ny, M. Douay, P. Niay et C. Boisrobert, "Experimental synthesis of fi ber Bragg gratings using optical low coherence reftectometry", Appl. Phys. Lett. , 82(24), 4227-4229, (2003).

6. P. Krug and R. Stolte and R. Ulrich,"Measurement of index modulation along an optical fi ber Bragg grating", Optics Letters, 20(17), 1767-1769, (1995). 